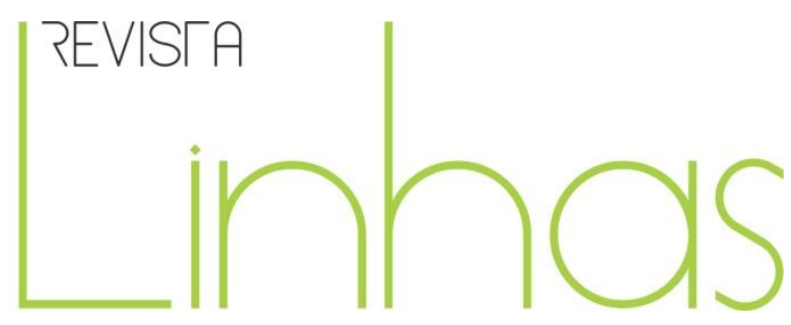

\title{
Professora Julia Wanderley: guardiã da memória iconográfica do Paraná
}

\begin{abstract}
Resumo
Esta pesquisa ressalta a importância do acervo iconográfico da professora Julia Wanderley, referente à memória popular e educacional de Curitiba, destacada nas suas coleções de postais e fotografias. Coleções estas que apresentam uma fonte de investigação significativa sobre o período final do século XIX e inicial do XX no Paraná. Julia Wanderley foi pioneira no Paraná ao pedir permissão para frequentar a escola normal, obtendo permissão e tornando-a mista. Um dos atributos designados a esta personagem social, além de 'professora exemplar', 'magnânima colecionadora' é o de 'guardiã da memória' do Paraná. É possível afirmar que o enquadramento da memória referente a Julia Wanderley foi alimentado pelo extremado zelo que teve por suas compilações de fotografias e postais. A metodologia utilizada se valeu da investigação de um conjunto de imagens, compostas por fotografias, postais, recortes de jornais, de revistas e até de pedaços de tecidos colocados no Livro íntimo (Diário) da professora Julia. Para fundamentar essa análise, recorremos prioritariamente a autores como Aumont (1993), Barthes (1984), Le Goff (1996), Machado Júnior (2010), Lissovsky (1998) e Manguel (2001). Nas coleções da professora, sua organização e preocupação histórica se revelaram de maneira particular, pois elas denotam costumes e comportamentos que afirmavam um caráter social distinto e modelar que buscava certa hegemonia cultural. A coleção iconográfica da Professora Julia é muito solicitada, constituindo-se em significativas representações da sociedade paranaense. Essas imagens percebidas como fontes históricas nos instigam a ler uma totalidade de ideias que permeavam um período/tempo.
\end{abstract}

Palavras-chave: Julia Wanderley. Professoras. Paraná. História.

Educação. Curitiba. Memória.

\section{Para citar este artigo:}

ARAUJO, Silvete aparecida Crippa de. Professora Julia Wanderley: guardiã da memória iconográfica do Paraná. Revista Linhas. Florianópolis, v. 18, n. 37, p. 283-302, maio/ago. 2017.

\section{DOI: $10.5965 / 1984723818372017283$}

http://dx.doi.org/10.5965/1984723818372017283

\footnotetext{
${ }^{1}$ Fragmentos desta pesquisa foram apresentados no XII EDUCERE - PUC (PR/2015).
}

\section{Silvete Aparecida Crippa de Araujo}

Universidade Federal do Paraná UFPR - Brasil silvetecrippa@gmail.com

\footnotetext{
(1)
} 


\title{
Professor Julia Wanderley: guardian of the iconographic memory of Paraná State
}

\begin{abstract}
This research reinforces the importance of the iconographic collection of Professor Julia Wanderley, related to the popular and educational memory of Curitiba, which is highlighted in this collections of postcards and photographs. They present a significant source of research on the latter part of the nineteenth and early twentieth century in Paraná. Julia Wanderley was a pioneer in Paraná when she asked for permission to attend a regular teacher education school, obtained permission and turned it into a mixed school. Besides "exemplary teacher" and "magnanimous collector", one of the attributes assigned to this social character, is "guardian of the memory" of Paraná State. It may be asserted that the framework of the Julia Wanderley related memory was fueled by the extreme zeal she had for her compilations of photographs and postcards. The methodology that was used avails itself of a set of images, consisting of photographs, postcards, newspaper clippings, magazines and even pieces of cloth inside the personal book (Diary) of Professor Julia. To support this analysis, we primarily turn to authors like Aumont (1993), Barthes (1984), Le Goff (1996), Júnior (2010), Lissovsky (1998) and Manguel (2001). The organization and the historical concern is revealed in a special way in the teacher's collections, once they denote habits and behaviors that claim a distinct and exemplary social nature that seeks a certain cultural hegemony. The iconographic collection of Professor Julia is very much requested, comprising a significant representation of the society of Paraná. These images perceived as historical sources encourage us to read a totality of ideas that permeated that period of time.
\end{abstract}

Keywords: Julia Wanderley. Teachers. Paraná. History. Education. Curitiba. Memory. 
O homem que perdeu sua experiência - e com ela, sua memória - é aquele que está se transformando em autômato, submetido a uma economia de gestos repetitivos e mecânicos, e que são como aqueles em uma linha de produção industrial, indiferentes ao

tempo. (LISSOVSKY, 1998)

\section{Introdução}

O presente texto resulta da pesquisa biográfica ${ }^{2}$ desenvolvida para a construção da dissertação de Mestrado defendida em 2010, denominada "Professora Julia Wanderley, uma mulher-mito (1874 - 1918)”. Ao investigar essa temática, sentiu-se a necessidade de analisar com maior apreço as coleções que Julia Wanderley possuía, especificamente as fotografias e cartões postais, os quais tiveram significativa importância na construção e fortalecimento de sua memória ${ }^{3}$, configurando representações e atributos que foram se conformando em torno de sua pessoa e revelando a cultura de uma época.

O período estudado é o do final do século XIX e início do XX em Curitiba, isto é, o período de transição do regime imperial para o republicano. Cenário de mudanças em decorrência do final da escravidão, instalação da República, incentivo a industrialização e ampliação da imigração no Brasil. É preciso lembrar que, neste período, 'ser civilizado', como os franceses e europeus em geral, significava maior presença feminina (e registro desses momentos) em acontecimentos da vida social (CORBIN, 1991; D'INCAO, 2004). E foi o que Julia Wanderley fez, como várias outras mulheres deste período fizeram, de forma mais ou menos sistemática e diversificada: participaram com maior amplitude na vida pública. As coleções da professora Julia, sem dúvida, ricas em informações, caprichosamente ordenadas durante anos, não podem deixar de ser consideradas como elemento representativo dos 'novos tempos'.

\footnotetext{
${ }^{2} \mathrm{O}$ novo olhar do historiador biográfico deve se deslocar a todo o momento do indivíduo à sociedade, da narração à explicação, da unidade à fragmentação e do público ao privado (SCHMIDT, 1996, p. 186).

${ }^{3}$ Memória, entendida como um fenômeno coletivo e social, ou seja, construído coletivamente e submetido a flutuações, transformações e mudanças constantes (POLLAK, 1992, p. 201). Também compreendida enquanto vida sempre carregada por grupos vivos e nesse sentido, ela está em permanente evolução, aberta à dialética da lembrança e do esquecimento, inconsciente de suas deformações sucessivas, vulnerável a todos os usos e manipulações, suscetível de longas latências e de repentinas revitalizações (NORA, 1981, p. 8-9).
} 
A colecionadora Julia Augusta de Souza Wanderley ${ }^{4}$ nasceu no dia 26 de agosto de 1874 em Ponta Grossa, cidade do Paraná. A família de Julia Wanderley, em 1877, veio a se estabelecer em Curitiba; e ela viveu na cidade até a data de seu falecimento, em 05 de abril de 1918.

Em 1890, Julia Wanderley matriculou-se na Escola Normal de Curitiba junto a outras três moças, (legitimando esta escola como promíscua ${ }^{5}$ ) e formou-se no final de 1892. Foi a primeira professora normalista nomeada pelo governo estadual. Logo após, em 1895, passou a exercer também a direção da escola Tiradentes; em meados dos anos de 1914, também foi diretora do Grupo Escolar Tiradentes e, na sequência, diretora de Escola Intermediária e membro do Conselho Superior do Ensino Primário do Paraná.

Julia Wanderley se mostrava interessada nas novidades da época e colecionava imagens de cartões postais e fotografias referentes aos fatos de destaque do seu tempo, além de fotos de família e amigos. O presente trabalho pretende ressaltar a importância das suas coleções iconográficas para a história, e em especial para a história da educação, bem como a memória que ela procurou preservar.

\section{Julia Wanderley: guardiã da memória familiar}

A fama de colecionadora, guardiã da memória de Curitiba especificamente, atribuída a Julia Wanderley é constantemente revitalizada (exercendo as imagens lugares de memória ${ }^{6}$ ). Sua organização se revelava de maneira particular, destacando-se em seu meio pelo extremado zelo que tinha por suas coleções de fotografias e cartões postais, de recortes de jornais, de revistas e até de pedaços de tecidos de roupas "para o Julinho"”, registrado em seu Livro íntimo ou Diário. De acordo com Araujo (2013, p. 72), “Julinho" era a forma carinhosa como a professora Julia se referia ao seu filho.

\footnotetext{
${ }^{4}$ Julia Augusta de Souza Wanderley, depois de casada, Julia Augusta de Souza Wanderley PETRICH, forma como ela também assinava seus documentos. Usaremos o nome pelo qual a professora é mais rememorada até os dias de hoje: JULIA WANDERLEY.

${ }^{5}$ Escola promíscua era a escola que aceitava alunos de ambos os sexos na mesma classe.

${ }^{6}$ Lugares de memória pertencem a dois domínios: simples e ambíguos; naturais e artificiais, imediatamente oferecidos a mais sensível experiência e, ao mesmo tempo, sobressaindo da mais abstrata elaboração. Com efeito, nos três sentidos da palavra: material, simbólico e funcional simultaneamente (NORA, 1981, p. 21).

7 Julio Petrich da Costa era na realidade filho biológico de Minervina, a irmã mais nova de D. Julia. Para saber mais, ver ARAUJO (2013).
} 
O Livro íntimo ou Diário de Julia Wanderley é um testemunho de seu amor maternal, no qual são vislumbradas páginas com contornos da "mão do Julinho" (como está registrado no diário), com oito, com nove e com dez anos de idade, as quais representam as marcas visíveis do crescimento do menino; igualmente, se verificam muitos desenhos, os primeiros escritos de Julinho e uma coleção de pequenas amostras de tecido para roupas do menino, cuidadosamente dispostas e coladas, lado a lado, em mais de uma folha, com a discriminação do tecido e valor. No diário, além dos registros sobre “Julinho", constavam recortes de jornais com anúncios de médicos e escolas, e também os que informam sobre o aniversário de Julio Petrich da Costa e sobre doações para instituições de caridade que o casal Petrich fazia em nome do filho, uma prática social da época atribuída a gente de bem $^{8}$. Também fotos que demonstravam o crescimento do menino e as atitudes de uma criança educada.

As imagens da coleção da professora Julia eram lembranças nítidas de uma vida, representando uma memória e apontando os lugares de realização histórica, testemunhos de uma existência. De acordo com Santaella (2012, p. 17-19), as imagens são “representações" porque são criadas e produzidas pelos seres humanos nas sociedades em que vivem e diferem de acordo com a finalidade a que se prestam. Coleções que quando perquiridas nos fazem reencontrar (no sentido de retomar) os dias antigos, tempo perdido que a memória corrobora em ressuscitar. "A memória introduz o passado no presente sem modificá-lo, mas necessariamente atualizando-o" (SEIXAS, 2004, p. 50, grifo do autor).

Julia Wanderley, entre suas coleções, coligiu, organizou e encadernou as revistas Fon-Fon e Careta, periódicos que engendravam um espaço privilegiado para divulgar imagens, costumes e comportamentos que afirmavam um caráter social distinto e modelar buscando certa hegemonia cultural. As revistas passam a ter maior diversidade e acentuavam a sua produção no início do século XX; Júnior (2012 p. 46) menciona que as revistas ilustradas se tornaram produtos constituintes de uma empresa mercantil a qual buscava sustentar-se pela permanência de seu produto no mercado de consumo e deviam corresponder às expectativas de um determinado público consumidor, visando

\footnotetext{
${ }^{8}$ Segundo Schaeffer; Britto; Kleinke (1985, p. 20), também existiriam neste material, orientações sobre educação e estímulo ao futuro profissional de Julinho. Para realizar essa pesquisa foi possível consultar apenas parte do Livro íntimo ou Diário da professora Julia Wanderley.
} 
atingir e/ou ampliar o maior número de leitores. Ao que se constata, Julia Wanderley fez parte deste seleto público leitor.

Além de sua coleção de revistas, de outras coleções e de breves escritos, Julia Wanderley se mostrou, mas de maneira peculiar, como uma arquivista. Colecionar, contudo é uma ação que de certa forma mostra os hábitos, paixões e excentricidades comuns entre os colecionadores, e pode representar uma mania ou até uma arte. Para Schapochnik (1998, p. 433), o colecionador culmina a paixão individual pela propriedade privada, o que pode ser convertido em fuga apaixonada, refúgio "em meio a objetos que são também narcísicos do eu".

A fotografia usada para solenizar e eternizar momentos da vida particular, familiar ou social foi um artifício muito utilizado por Julia Wanderley, inclusive para reforçar o seu lugar de memória. Contudo, assegura Silva (2008, p. 36), a invenção da fotografia9 "em meados do século XIX e sua evolução nos conduzem ao fato irreversível de que todos atuam para os outros - se o outro não existisse, eu não poderia vê-lo, mas ele também não poderia me ver".

As fotografias de família, ou seja, os álbuns familiares se revelavam por uma sensação em que ainda preponderava um valor de culto, para solenizar e eternizar os grandes momentos da vida familiar reafirmando um sentimento de unidade. Schapochnik (1998, p. 460), observa que as fotografias isoladas ou reunidas num álbum apresentam a qualidade de ser um dos mais preciosos "lugares da memória familiar". Investida de um valor simbólico e afetivo, as fotografias ficavam sob a tutela de um guardião da memória familiar e Julia Wanderley, nesse caso, se revelou esta guardiã, uma arquivista da memória familiar, inclusive fazendo observações pertinentes a cada época e a cada acontecimento na maioria das imagens colecionadas, como se observa na figura 1, uma forma tradicional de retratar uma família burguesa no início do século XX.

\footnotetext{
${ }^{9}$ A fotografia surgiu na década de 1830 , como resultado da feliz conjugação do engenho, da técnica e da oportunidade. Marcada por polêmicas ligadas aos seus usos e costumes (MAUAD, 2008, p. 29-30).
} 


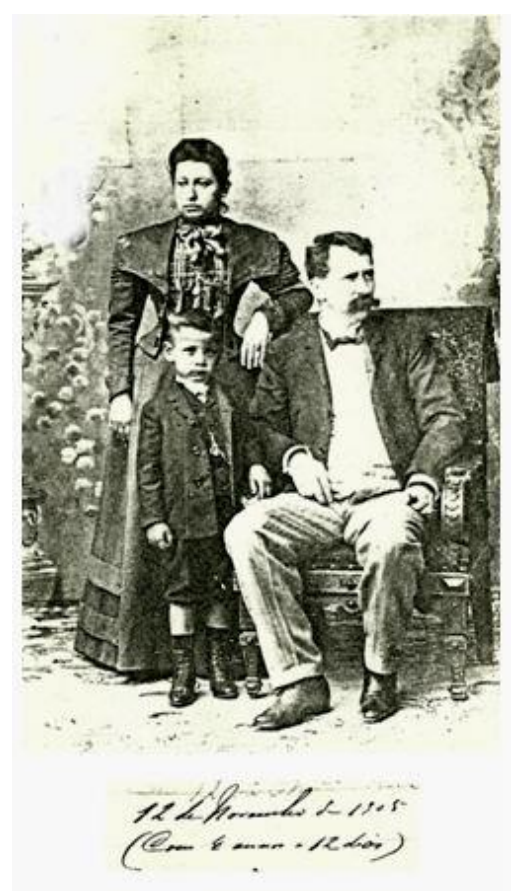

Figura 1 - Julia, Marido e Filho

Fonte: Acervo da Biblioteca da MUNESP/SBEE.

Julia Wanderley, através de seu repertório de imagens e de seus álbuns fotográficos ${ }^{10}$, reforçou o modelo de organização de corpos utilizado para fotografar a família no final do século XIX e início do século XX, no qual o homem, tido como provedor, chefe da família, tinha o lugar de destaque, pois ficava geralmente sentado numa posição referente a um suposto reinado. O álbum de família anuncia um tempo historiado e ritualizado, orienta um olhar para o futuro e para observadores restritos. $\mathrm{O}$ "álbum é foto apenas pela metade: a outra metade se deve a quem coleciona e o conta" (SILVA, 2008, p. 38).

O álbum pode ser definido com um rito, pois congela momentos desde os ritos de passagem até os fragmentos do dia a dia de crianças, mulheres e homens. E se é rito, é memória que se investe de esquecimentos, marcas, olhares, pedaços de lugares que uma parte da vida registrou: o tempo perdido, o qual Julia Wanderley buscou eternizar e o conseguiu com eficiência. São muitos os tempos colecionados por ela, muitas das fotografias guardadas e arquivadas no álbum familiar acompanham o crescimento do seu filho, em que são verificadas imagens do batizado, da primeira comunhão, de festas entre outras.

\footnotetext{
${ }^{10}$ Materiais (fotos e postais) que podem ser encontrados na Casa da Memória de Curitiba e no Museu Nacional do Espiritismo/Sociedade Brasileira de Estudos Espíritas - MUNESP/SBEE.
} 
Os retratos de Julio Petrich variam; supostamente algumas fotos foram tiradas pela professora, por familiares ou amigos, mas muitas foram feitas em estúdio fotográfico, costume da época. Analisando a história da fotografia, Machado Júnior (2012, p. 72), nos lembra "que as elites procuraram moldar em suas crianças alguns costumes adotados pelos adultos de acordo com a cultura fotográfica social da época”, portanto o comportamento fotográfico de Julia Wanderley atendia aos padrões de um tempo, quando reconhecemos na foto o disciplinamento dos corpos. Barthes (1984) analisou o modo como as pessoas eram retratadas no final do século XIX, e podemos afirmar que essa forma se prolongou até meados do século XX.

De forma geral, o "ato fotográfico tornou-se um fator influente no comportamento social, visto que todos aqueles que desejaram 'dar-se a ver' e mobilizaram-se para 'deixar registrar' pela máquina fotográfica, visaram posteriormente, a promoção de suas imagens" (MACHADO JÚNIOR, 2012, p. 53, grifo do autor). A fotografia expressa um momento ativado pelo clique de uma máquina, o qual, congelado no tempo, representa essa "coisa um pouco terrível que há em toda fotografia: o retorno do morto" (BARTHES, 1984, p. 20). De certa forma, quem é fotografado e rememorado por esta ou aquela foto nunca morre, a fotografia de pessoas, amigos e familiares é uma maneira de dizer baixinho ao nosso ouvido 'Olhe!', 'Estou aqui', 'Lembrem-se de mim!'. Julia Wanderley ao legar sua coleção à posteridade deixa-nos essas exclamações.

Julia nos dá pistas de como gostaria de ser rememorada: esposa, mãe dedicada, professora, diretora e amiga, representações expressas nas imagens configuradas em seu acervo iconográfico. Diante da objetiva de uma câmera fotográfica, a foto-retrato, conforme assegura Barthes (1984, p. 26-27), engendra quatro imaginários: “Diante da objetiva, sou ao mesmo tempo: aquele que eu me julgo; aquele que eu gostaria que me julgassem; aquele que o fotógrafo me julga e aquele de que ele se serve para exibir sua arte". Quando nos deparamos com a fotografia antiga, percebemos que ainda há um resquício do comportamento utilizado para posar para os retratos pintados, haja vista que os fotografados/modelos preservam ainda um ar estático e específico para cada momento ou lugar, não uma mímica.

Contudo, a fotografia pode nos dizer muito mais do que os retratos pintados, pois ela permite o acesso a um conjunto de elementos periféricos e de base, nos fornece uma 
coleção de objetos parciais e elementos no seu entorno que podem favorecer um estudo histórico mais ampliado e apurado, "a fotografia tem com a história a mesma relação que o biografema com a biografia" (BARTHES, 1984, p. 51). Ao analisar uma imagem fotográfica, a exemplo da figura 2, como uma fonte histórica, é possível construir uma pesquisa de muito fôlego e rica em detalhes, que envolvem um rico exercício de interpretação da imagem e do contexto em que se encontra. Na imagem abaixo, uma escola para meninas, mas podemos perceber também a presença de meninos.

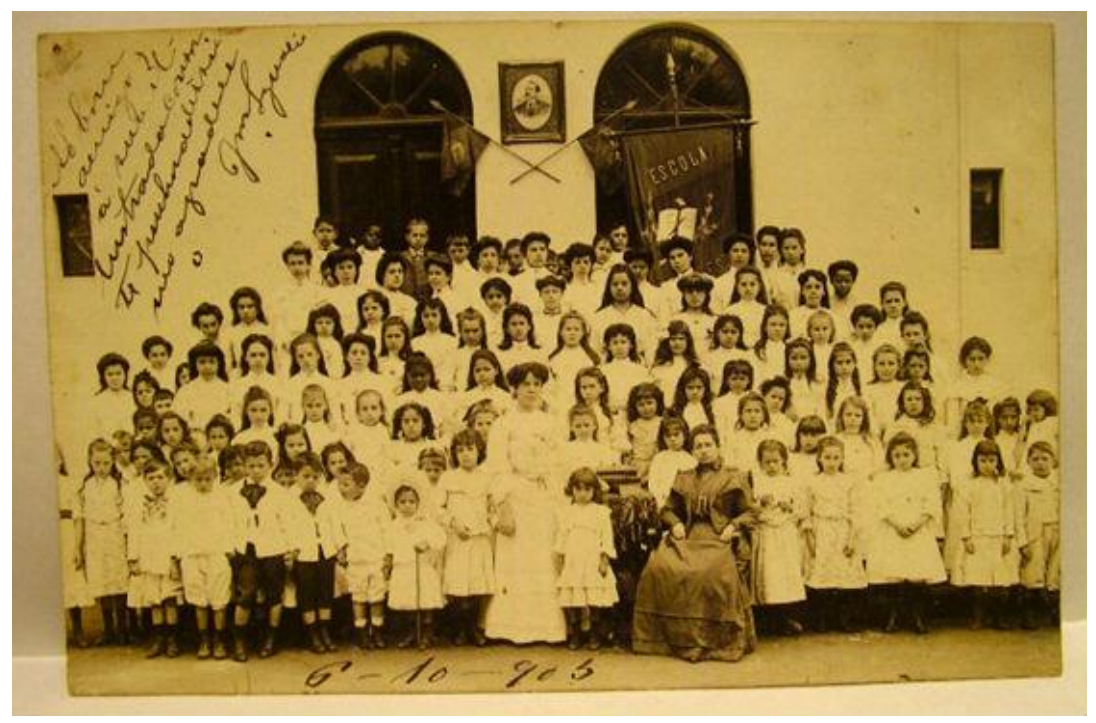

Figura 2 - Julia Wanderley e alunos

Fonte: Acervo da Biblioteca da MUNESP/SBEE.

A foto-retrato se investe de um sentido, ou seja, de uma intenção em que há necessidade de representar aspectos de uma vida, um momento sutil em que o fotografado não é nem sujeito e nem objeto; para Barthes (1984, p. 27-28), o fotografado é antes “um sujeito que se sente tornar-se objeto”. Naquele exato momento do 'clic' vive uma microexperiência da morte (dos parênteses): torna-se verdadeiro espectro. Segundo Lissovsky (1998, p. 26), a "foto oscila entre aquilo que lhe escapa e isto que nela se infiltra”, o gesto, representado pelo 'clic', consuma a espera e contém a renúncia que todo fotógrafo deve fazer para que haja uma imagem fora de si, portanto é necessário ao historiador saber ler uma imagem naquilo que ela tentou representar e aquilo que de fato ela representa na sua totalidade.

Muitas são as fotos encontradas de Julia Wanderley com a família, alunos e um pouco menos com amigos; elementos que a ajudaram a marcar sua memória como exímia 
colecionadora, mulher forte e exemplar. Entretanto, devemos destacar que as coleções iconográficas da professora foram de suma importância para a história do Paraná, haja vista que suas fotografias e postais expressam várias imagens/documentos e imagens/monumentos ${ }^{11}$ significativos para o Paraná, os quais marcam uma materialidade passada.

\section{Julia Wanderley: produzindo e guardando uma memória social}

Além de colecionar fotografias de Julio Petrich, seus familiares, alunos e amigos, Julia Wanderley também possuía uma coleção de fotos e cartões postais que registravam temas da vida cotidiana e os momentos considerados excepcionais do período que viveu em Curitiba, constituindo-se nas representações da sociedade paranaense. Essas imagens nos instigam a interpretar uma totalidade ou ideia que permeiam um período/tempo.

Essas fotografias e postais, portanto, são imagens que concorrem para a localização social e política de um tempo específico, haja vista que captam transformações da urbe (praças, monumentos, etc.), eventos artísticos, homenagens públicas e festas (religiosas ou não). E Julia bem expressa esse momento que avança sobre o século $X X$, com muito cuidado e ordem; uma mulher disciplinada e zelosa na forma como foi lembrada por seus pares, a exemplo de sua ex-aluna Maria Nicolas, que faz referência a ela, que era "ordenada em todos os seus atos, pode-se dizer que era disciplinada militarmente" (NICOLAS, 1977, p. 182).

Quando nos deparamos com fotografias, especialmente para fazer um trabalho sobre a história, considera-se salutar a comparação que Barthes (1984, p. 25) utiliza sobre a fotografia, a qual segundo ele nos proporciona a "história dos olhares"; a partir deste olhar novo sobre o antigo, podemos realizar, construir uma ponte que nos permita relacionar passado e presente. E Lissovsky (1998, p. 26) complementa que pelas imagens fotográficas, a partir das pistas e/ou respostas e das indagações feitas no presente sobre

\footnotetext{
${ }^{11}$ Para Le Goff, a história representa a forma científica da memória coletiva, é o resultado de uma construção, sendo que os materiais que a imortalizam são o documento e o monumento. Para o autor, "o que sobrevive não é o conjunto daquilo que existiu no passado, mas uma escolha efetuada quer pelas forças que operam no desenvolvimento temporal do mundo e da humanidade, quer pelos que se dedicam à ciência do passado e do tempo que passa, os historiadores. Estes materiais da memória podem apresentarse sob duas formas principais: os monumentos, herança do passado, e os documentos, escolha do historiador" (LE GOFF, 1996, p. 535).
} 
o passado, construímos histórias. Ressaltando que a imagem em si não explica com profusão um período, contudo nos convida e instiga a recriá-lo, revivê-lo e a rememorá-lo.

Ao contemplar as fotos e postais da coleção de Julia Wanderley, encontramos vestígios de um passado nas imagens, e estas pretendem trazer à vida os acontecimentos passados e quando nos propomos a analisar tais imagens, eis que ressuscitamos memórias que podem ser utilizadas como elementos primordiais à história; provavelmente era o que pretendia D. Julia ao arquivar imagens.

Julia Wanderley também apoiava as causas do Estado em que nasceu e viveu. Em sua coleção, encontram-se imagens do jornal A República, de 13 de julho de 1904, o qual informava a participação da professora e suas alunas no "meeting de estudantes" que aconteceu na Praça Tiradentes (marco zero de Curitiba) em repúdio pela deliberação política do Governo Federal frente à questão do Contestado, que privilegiou o estado de Santa Catarina em detrimento do Paraná ${ }^{2}$, conforme figura 3. Verificamos mais um atributo endereçado a Julia Wanderley, o de mulher politizada.

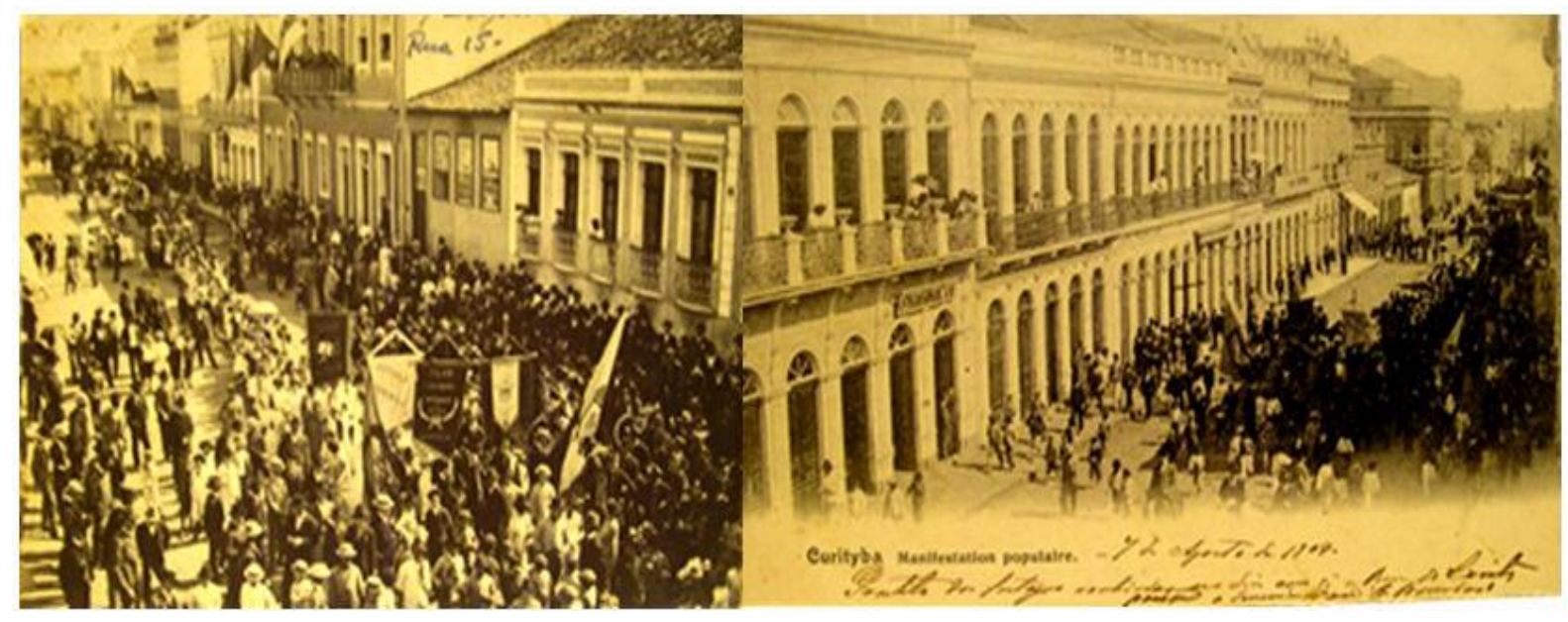

Figura3 - Protesto sobre a causa do Contestado. Fonte: Acervo da Biblioteca da MUNESP/SBEE

Nas fotografias e nos postais que Julia Wanderley colecionou, vários eram relativos ao tema desta disputa. As imagens devem ser assimiladas com base na relação do indivíduo ou fato retratado e contexto social vigente, portanto, afirma JÚNIOR (2012,

\footnotetext{
${ }^{12}$ Sobre a questão do Contestado, entre outros, veja: Gallo, 1999; Machado, 2004.
} 
p. 59), que "a imagem fotográfica por si só não possui significados, exigindo a presença de um receptor", o que envolve uma problemática que consiste em "como perceber o que se encontra aparentemente invisível na imagem". Tal questão nos convida a perceber que a professora Julia Wanderley apresenta através de suas imagens fotográficas os conflitos e posturas apropriados a um determinado tempo e a sua posição ideológica dos fatos. É significativo ressaltar que a fotografia "é uma representação de algo que realmente existiu e a representação de algo que foi intencionalmente criado" (MACHADO JÚNIOR, 2012, p. 79).

Outros aspectos históricos em forma de fotos ou postais foram arquivados pela professora Julia, como foi o caso das disputas por poder presidencial no Estado, impresso num postal representado por uma charge crítica; Saretta apud Machado Júnior (2012, p. 77-78) informa que a incompatibilidade entre o sistema político e econômico brasileiro começaria a ser mais acirrado na década de 1920 e desembocaria nas transformações que decorreram a partir de 1930. Contudo, anteriormente já se percebiam várias críticas ao governo instituído no país e nos estados especificamente. Questões provavelmente presentes no contexto social da época, registradas por Julia Wanderley e que a condicionaram como uma pessoa de engajamento político e crítica social, reveladora da cultura política e social da época. Importante apontar que fotografia e charge não contemplam os mesmos traços distintivos, "a fotografia sempre diz alguma coisa, mas não diz qualquer coisa, por mais que se procure manipulá-la" (MACHADO JÚNIOR, 2012, p. 79).

Entre muitos outros temas da história do Paraná, Julia Wanderley teve na sua coleção de postais a imagem referente a um acontecimento muito delicado ao estado do Paraná, que foi a Revolução Federalista e a tragédia ocorrida com o Barão de Serro Azul ${ }^{13}$, assunto proibido até os meados de 1940 no Estado. Vislumbra-se com isso que os silêncios políticos não sobrepujem as vozes dos indivíduos. É possível silenciar um acontecimento de grande impacto social eternamente? Jamais! A figura 4 confirma essa hipótese.

\footnotetext{
13 Ildefonso Pereira Correia, barão do Cerro Azul (Paranaguá1849 - Morretes1894), proprietário rural e político brasileiro. Foi o maior exportador de erva-mate do Paraná. Durante a revolução Federalista, ele e outras cinco pessoas proeminentes da cidade de Curitiba foram executadas sumariamente na Serra do Mar sem qualquer processo legal ou acusação formal. Para saber mais, ver A Última Viagem do Barão do Serro Azul de VARGAS (2004) e/ou o filme O Preço da Paz.
} 


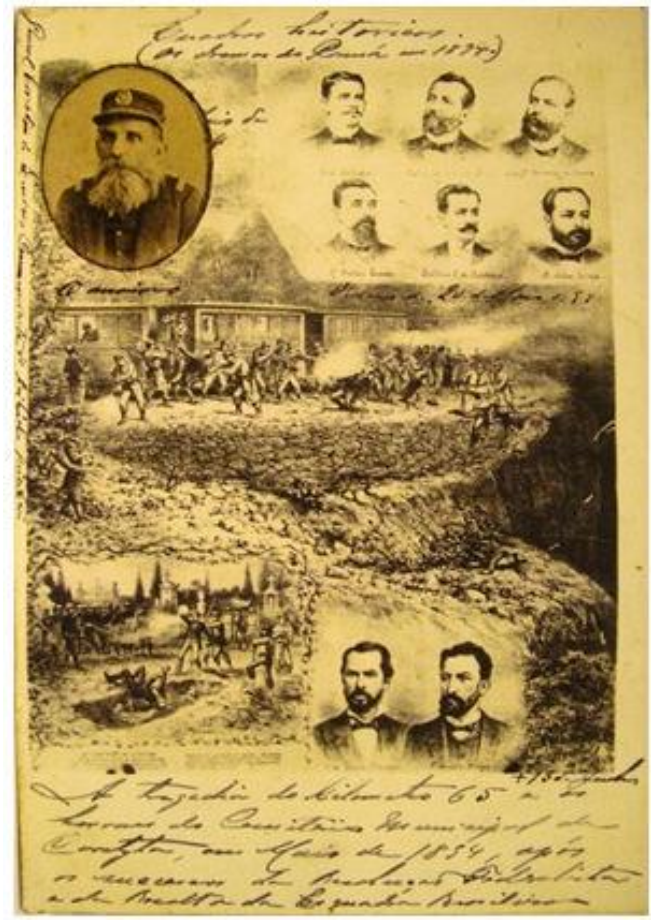

Figura 4 - Revolução Federalista e a Tragédia do Barão de Serro Azul

Fonte: Acervo da Biblioteca da MUNESP/SBEE.

São estes acontecimentos que propiciam que vozes sejam ouvidas e o historiador, curioso e atento, deve tentar dar uma ordem, ou seja, situar com maior propriedade o tempo, o espaço e as vozes condizentes e destoantes referente a tal fato. A imagem como vestígio de um momento, é construída pelo espectador, bem como também constrói o espectador (AUMONT, 1993, p. 81). Julia Wanderley, além de colecionar postais e fotos que simbolizavam de certa maneira o contexto social e político do momento, igualmente apresentava os acontecimentos sociais que traziam à cidade um ar de modernidade, como as mulheres vistas de forma geral circulando mais pelos espaços públicos. As imagens da coleção de Julia revelam e narram uma nova cultura que se pretendia estabelecer, a de modernidade.

Este processo de homogeneização cultural sobre a população heterogênea, a fim de se consolidar uma identidade nacional, terá início no final do Império e continuará nas primeiras décadas da República; incidirá fortemente sobre a escola primária, as práticas pedagógicas e sobre a profissão docente representando a construção de uma nova cultura escolar ${ }^{14}$.

\footnotetext{
${ }^{14}$ Cultura escolar aqui compreendida como aquela que não pode ser estudada sem a análise precisa das relações conflituosas ou pacíficas que ela mantém, a cada período de sua história, com o conjunto das
} 
O novo, o moderno e o civilizado representavam o ideal republicano se estabelecendo no tecido social; entrando em cena, e assim as imagens tomam lugar das percepções diretas e, dessa forma, podemos narrar as imagens tendo em vista a compreensão do interesse, lugar e tempo em que se encontravam. Manguel (2001, p. 21) menciona que "qualquer imagem admite tradução em uma linguagem compreensível, revelando ao espectador aquilo que podemos chamar de Narrativa da imagem". A professora Julia também colecionou várias imagens que representavam tanto as manifestações sociais como as de lazer dos curitibanos; é o que se verifica na figura 5 .

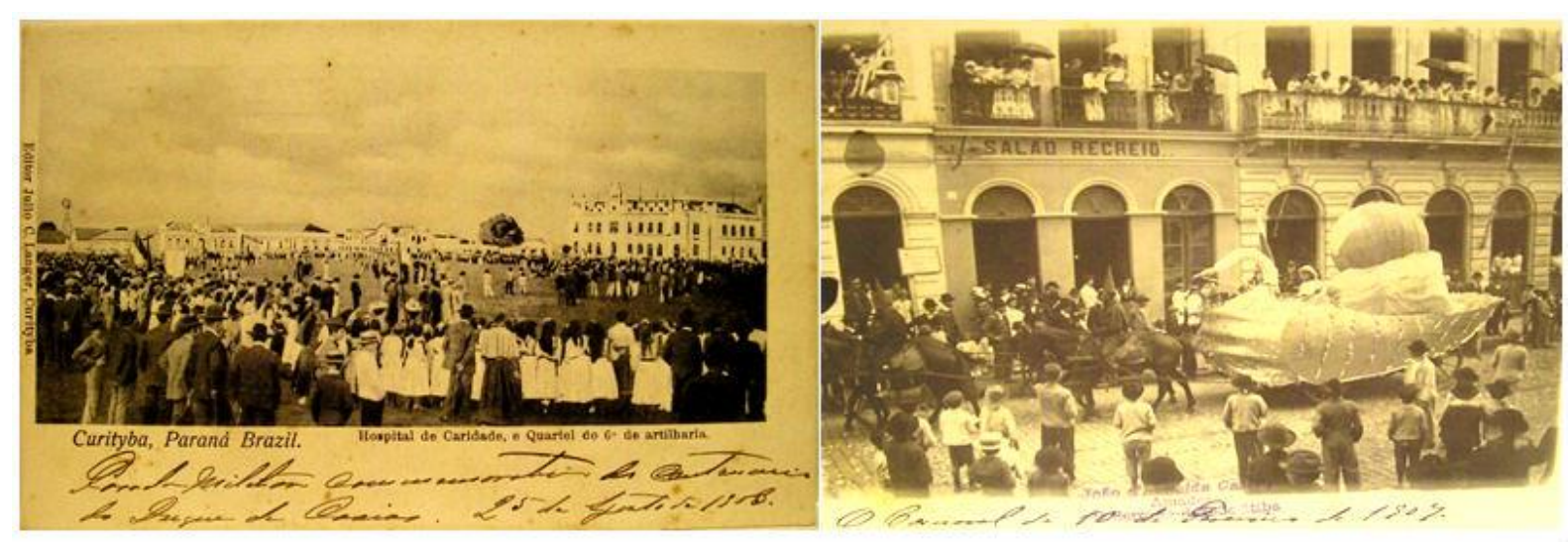

Figura 5 - Parada Militar - Homenagem a Duque de Caxias e Carnaval de Curitiba - 1907 Fonte: Acervo da Biblioteca da MUNESP/SBEE.

Ao observar as imagens acima do acervo de Julia Wanderely, é possível compreender uma narrativa subliminar sobre as consolidações e os anseios que foram se efetivando em decorrência da nova organização que se estabelecia no país como a ocorrência das festas cívicas (republicanas), a exemplo da parada militar em homenagem a Duque de Caxias e as festas populares como o carnaval $^{15}$, promovido no centro da capital do Paraná. Também as festas promovidas pelos imigrantes ${ }^{16}$ fazem parte do

culturas que lhe são contemporâneas: cultura religiosa, cultura política ou cultura popular. (JULIA, 2001, p. 10).

${ }^{15}$ Embora a elite e classe média preferissem o carnaval dos clubes, de acordo com o modelo europeu e, assim, se proteger do conglomerado popular.

${ }^{16}$ Os fluxos migratórios com destino ao Paraná se intensificaram a partir da década de 1850 , quando o Estado obteve sua independência e deixou de ser província de São Paulo. Nesse momento, o governo local desenvolveu políticas para atrair novos migrantes a fim de promover o desenvolvimento econômico do Estado. Entre os anos de 1853 e 1886, o Paraná recebeu aproximadamente 20 mil migrantes que formaram 
acervo da professora; essas festas eram uma maneira de preservar e ressaltar os costumes e a identidade de um grupo.

Outras representações são narradas pelas imagens fotográficas como a chegada da industrialização no estado que fomentou novas formas de organização do trabalho. Parafraseando Machado Júnior (2012, p. 89), houve locais, bem como acontecimentos que foram privilegiados para se fazer o registro fotográfico e Julia Wanderley bem soube arquivar tais imagens e fortalecer a memória do estado do Paraná; imagens que serviram para identificar certo número de símbolos socioculturalmente elaborados. Reconhecer o mundo visual nas imagens pode ser útil na realização de várias pesquisas, além de proporcionar também um prazer específico, resultante da satisfação psicológica pressuposta pelo fato de "reencontrar" (AUMONT, 1993, p. 83).

Julia Wanderley também coligiu imagens-memórias de uma nova cultura escolar que foi se configurando no Paraná com a constituição dos Grupos Escolares e a feminização da Escola Normal, da qual ela foi também fomentadora. Essas instituições deveriam estar pautadas por uma nova organização administrativo-pedagógica, as quais deveriam promover modificações no tempo e espaço escolares, nos currículos, na forma de gestão e na postura didática do professor sob o símbolo da ordem e do progresso.

As fotos escolares perquiridas configuram um contexto que identifica a importância da organização dos corpos ao serem fotografados, e foram imagens que Julia Wanderley fortaleceu ao selecioná-las. Embora houvesse toda uma organização e postura como exigências para ser retratado, percebe-se que existiram os insubordinados, que fugiam ao padrão predeterminado (de forma consciente ou não); como se observa na figura 6, em que se registra o menino com o dedo no nariz ao lado da professora Julia (sentada ao centro) no momento do 'clic' fotográfico. Ao analisar uma imagem, devemos ter a convicção de que além de ser uma imagem do real, a fotografia é um vestígio diretamente calcado sobre o real, como uma pegada (BENCOSTTA, 2011, p. 398).

diversas colônias no território. Os principais grupos foram de imigrantes alemães, poloneses, ucranianos, italianos, portugueses, holandeses, espanhóis, árabes, argentinos, poloneses e japoneses (WACHOWICZ, 1995). 


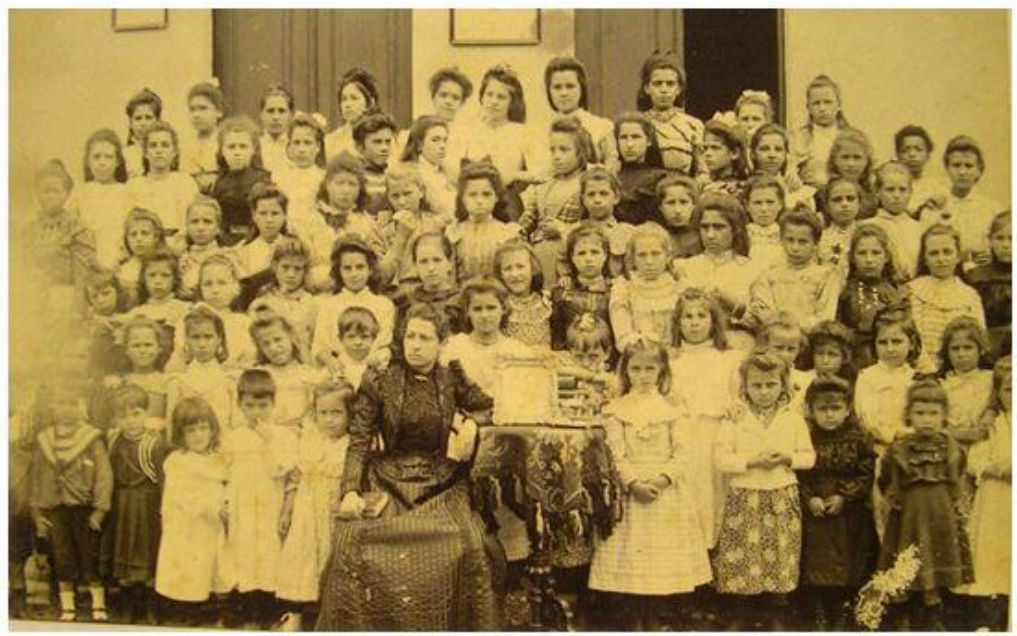

Figura 6 - Turma de Julia Wanderley Fonte: Acervo da Biblioteca da MUNESP/SBEE.

As imagens fotográficas do universo escolar da coleção de Julia Wanderley representam uma vasta fonte de pesquisa para a história da escolarização no Paraná nas primeiras décadas do século XX e suas representações. Estando a professora Julia entre as primeiras moças a participar presencialmente da Escola Normal (1891-1892), entendese que foi imperioso o recrutamento de profissionais femininas para atender à difusão da educação entre uma população de origens e hábitos diversificados e que precisavam ser 'morigerados'. À vista disso, nas primeiras décadas do século XX, o crescente número de mulheres professoras esteve intimamente relacionada à remodelação e difusão da escola primária.

A feminização do magistério evidenciada no final do regime Imperial foi fortalecida e ampliada após a institucionalização da República, e esteve intimamente relacionada ao crescente desinteresse dos homens pela docência ${ }^{17}$. Analisando e comparando as fotos da figura 7, evidencia-se que os rapazes que se formaram em 1905 estão em menor número do que as moças em 1907 na Escola Normal; o acervo fotográfico de Julia Wanderley guarda esta memória significativa de um tempo e reveladora da mudança de costumes. Podemos pensar juntamente com Bencostta (2011, p. 402), que sendo as fotografias escolares uma "fonte histórica carregada de sentido, a compreensão de sua representação somente será possível caso as informações resultantes da análise estiverem relacionadas ao contexto histórico no qual foram

\footnotetext{
${ }^{17}$ De acordo com LAGRAVE (1991), a feminização do magistério foi mais um episódio de "uma emancipação sob tutela" do que de uma luta por espaço no mundo educacional e do trabalho.
} 
produzidas".

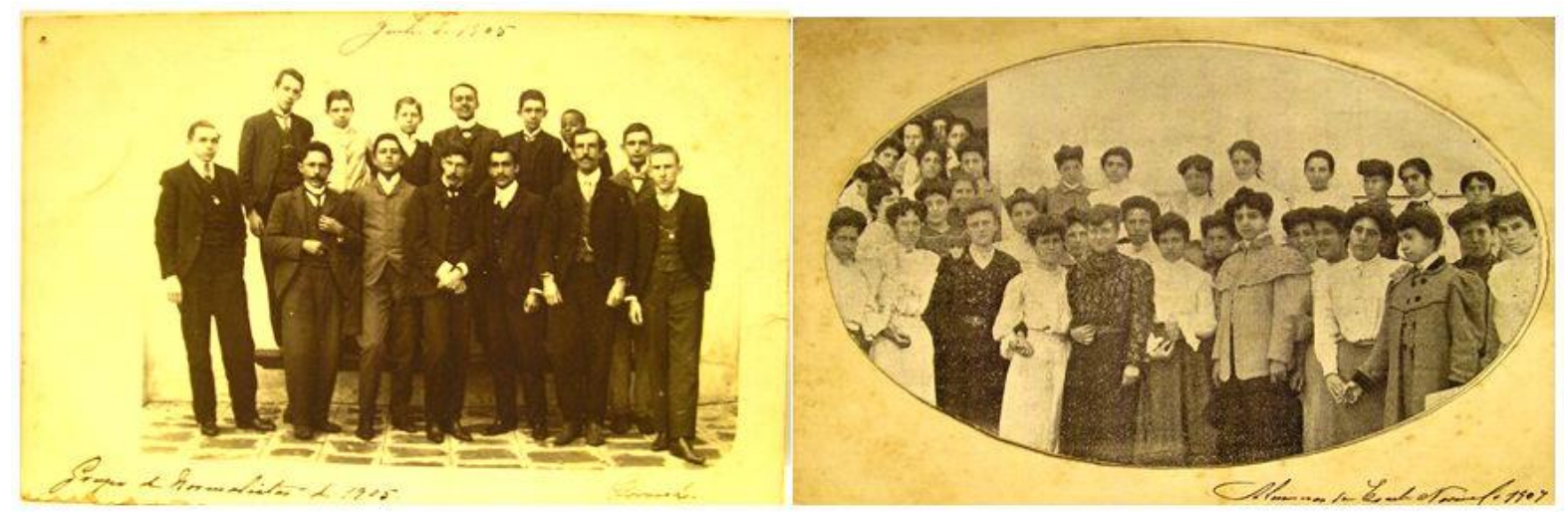

Figura 7 - Formatura dos alunos em 1905 e alunas da Escola Normal 1907 Fonte: Acervo da Biblioteca da MUNESP/SBEE.

Ressalta-se que as imagens fotográficas de propriedade de Julia Wanderley expressam anseios e necessidades de um país republicano, que aspirava ordem e progresso na configuração política e administrativa, bem como, na escolar. Arrolado a isso, depreendemos a necessidade, perante as imagens observadas, de ordem e organização nas escolas para educar os corpos e mentes dos alunos e, na cidade, a urbanização para educar e condicionar corpos e mentes da população de forma geral. Logo, a fotografia sendo uma valiosa fonte de pesquisa, enquanto interface entre história e memória, afirmamos que a imagem compreende, portanto, um suporte material da memória, uma testemunha de um "aconteceu assim", e logo podemos "verificar comportamentos, tradições, eventos tal como o fotógrafo os percebeu" (BENCOSTTA, 2011, p. 407).

A construção da memória de Julia Wanderley, de sua missão educativa, de importante guardiã da memória associa-se de forma explícita à tese da construção de uma nova nação, civilizada e moderna. E ela retrata este momento ao arquivar imagens de uma Curitiba e de um Estado que crescia, direcionava os ignorantes para a escola, os órfãos para os asilos, os doentes para os hospitais, os vadios para a cadeia e os dementes ao hospício. E a cidade de Curitiba de forma geral foi sendo urbanizada e saneada, tornando-se moderna e acolhedora aos olhos de Julia Wanderley e dos registros deixados através de suas coleções iconográficas. 


\section{Considerações Finais}

É necessário destacar que a diversidade de imagens fotográficas e postais que Julia Wanderley colecionou, e que ganharam ares de documento/monumento, são registros mecanizados de fragmentos de um mundo visual, deflagrados em vários momentos e espaços e "puderam ser interpretados como prova concreta de uma determinada realidade proposta" (MACHADO JÚNIOR, 2012, p. 52). Imagens que reunidas por Julia Wanderley condicionam o nosso olhar, se não estivermos atentos, e designaramIhe a insígnia de guardiã da memória paranaense.

Reconhecer a relação da coleção de fotos e cartões postais de Julia Wanderley com os novos padrões de visibilidade que se estabeleciam no Paraná do final do século XIX e início do XX deram suporte para compreender a memória que lhe foi consagrada: a de importante colecionadora. Para realizar tal intento, foi necessário situar Julia Wanderley, tentar compreender a sua intenção e a preocupação com a organização de suas imagens iconográficas, ou seja, interpretar e perquirir a memória que ela procurou preservar. Foi significativo analisar as imagens e ações que foram reproduzidas em um tempo e lugar específico, para assim bem entender as representações que elegeram Julia Wanderley depositária da memória paranaense.

Não é pretensão dar como concluída esta pesquisa, pois outros elementos podem ser analisados e discutidos referentes às coleções de Julia Wanderley e em referência à época desta distinta personagem histórica. 


\section{Referências}

ARAUJO, Silvete Aparecida Crippa de. Professora Júlia Wanderley: uma mulher-mito (1874-1918). Curitiba: Ed. UFPR, 2013.

AUMONT, Jacques. A imagem. Campinas: Papirus, 1993, p. 77-96.

BARTHES, Roland. A câmara clara: nota sobre a fotografia. Rio de Janeiro: Nova Fronteira: 1984, p. 11-91.

BENCOSTTA, Marcus. Levi. Memória e cultura escolar: a imagem fotográfica no estudo da escola primária de Curitiba. História, v. 30, n. 1, p. 396-411, 2011.

CORBIN, Alain. O segredo do indivíduo. In: Ariès, Philippe; Duby, George. (Dirs.). História da vida privada. São Paulo: Companhia das Letras, 1991. vol. 4, p. 419-501.

D'INCAO, Maria Ângela. Mulher e família burguesa. In: DEL PRIORE, Mary. (Org.). História das mulheres no Brasil. 7. ed. São Paulo: Editora Contexto, 2004, p. 223-240.

GALLO, Ivone Cecília d’Ávila. O Contestado, o sonho do milênio igualitário. Campinas: Ed. Unicamp, 1999.

JULIA, Dominique. A cultura escolar como objeto histórico. Revista Brasileira de História da Educação, n. 1, p. 9-44, jan./jun., 2001.

JULIA Wanderley: escritos, homenagens e fotografias. Biblioteca da Faculdade Dr. Leocádio José Correia - FALEC. Curitiba: 2000.

LAGRAVE, Rose Mary. Uma emancipação sob tutela. Educação e trabalho das mulheres no século XX. In: DUBY, George; PERROT, Michele (Orgs.). História das mulheres no Ocidente. Porto: Afrontamento, 1991, p. 505-543.

LE GOFF, Jacques. História e memória. 4.ed. Campinas: Editora da Unicamp, 1996.

LISSOVSKY, Mauricio. Sob o signo do "clic": fotografias e história em Walter Benjamin. In: FELDMAN-BIANCO, Bela; LEITE, Miriam Moreira (Orgs). Desafios da Imagem: fotografia, iconografia e vídeo nas ciências sociais. Campinas, SP: Papirus, 1998.

MACHADO JÚNIOR, Cláudio de Sá. Fotografias e códigos culturais: representações da sociabilidade carioca pelas imagens da revista Careta. Porto Alegre: Evangraf, 2012.

MACHADO, Paulo Pinheiro. Lideranças do contestado. Campinas: Ed. Unicamp, 2004.

MANGUEL. Albert. Lendo imagens: uma história de amor e ódio. São Paulo: Companhia das Letras, 2001.

MAUAD, Ana Maria. Poses e flagrantes: ensaios de história e fotografia. Rio 2008.

NICOLAS, Maria. Pioneiras do Brasil. Curitiba: [s.n.], 1977. 
NORA, Pierre. Entre memória e história: a problemática dos lugares. In: NORA, Pierre. Projeto história: história e cultura. São Paulo: Editora da PUC, 1981, p. 7-28.

POLLAK. Michel. Memória e identidade. Estudos Históricos, Rio de Janeiro, v.5, n. 10, p. 200-212, 1992.

SANTAELLA, Lucia. Leitura de imagens. São Paulo: Melhoramentos, 2012.

SCHAEFFER, Evanir; BRITTO, Evelise O.; KLEINKE, Rita de Cassia. Educadores do Paraná: vida e obra de Julia Wanderley. Curitiba: Faculdade TUIUTI, 1985.

SCHAPOCHNIK, Nelson. Cartões postais, álbuns de família e ícones da intimidade. In: NOVAIS, Fernando (Coord.); SEVCENKO, Nicolau (Org.). História da vida privada no Brasil: República: da Belle Époque à era do rádio. São Paulo: Companhia das Letras, 1998. v. 3, p. 423-512.

SCHMIDT, Benito Bisso. O gênero biográfico no campo do conhecimento histórico: trajetórias, tendências e impasses atuais e uma proposta de investigação. Revista Anos 90 (UFRGS), Porto Alegre, v. 6, p. 165-192, 1996.

SEIXAS, Jaci Alves de. Percursos de memória em terras de história: problemáticas atuais. In: BRESCIANI, Stella; NAXARA, Marcia (Orgs.). Memória e (res)sentimento: indagações sobre uma questão sensível. Campinas: Ed. Unicamp, 2004. p. 37-58.

SILVA, Armando. Álbuns de família: a imagem de nós mesmos. São Paulo: Senac, 2008.

UM OLHAR para o futuro: coleção Julia Wanderley. Boletim Casa Romário Martins. Curitiba: Fundação Cultural de Curitiba, 2005.

VARGAS, Túlio. A última viagem do Barão do Serro Azul. Curitiba: Ed. Juruá, 2004.

WACHOWICZ, Rui. História do Paraná. Curitiba: Editora Gráfica Vicentina, 1995, p. 25-37.

Recebido em: 27/01/2016 Aprovado em: 31/03/2016

Universidade do Estado de Santa Catarina - UDESC

Programa de Pós-Graduação em Educação - PPGE

Revista Linhas

Volume 18 - Número 37 - Ano 2017 revistalinhas@gmail.com 